\title{
Vitamin D deficiency is associated with metabolic syndrome in postmenopausal women
}

\author{
Eneida Boteon Schmitt, Jorge Nahas-Neto, Flavia Bueloni-Dias, Priscila Ferreira Poloni, \\ Claudio Lera Orsatti, Eliana Aguiar Petri Nahas*
}

Department of Gynecology and Obstetrics, Botucatu Medical School, Sao Paulo State University - UNESP, Sao Paulo, Brazil

\section{A R T I C L E I N F O}

\section{Keywords:}

Vitamin D

Postmenopausal women

Metabolic syndrome

\begin{abstract}
A B S T R A C T
Objective: To evaluate the association between vitamin D (VD) deficiency and risk factors for metabolic syndrome (MetS) in postmenopausal women.

Study design: Observational, cross-sectional cohort study.

Main outcome measures: In this study, 463 women, aged 45-75 years, with amenorrhea $>12$ months, without VD supplementation or established cardiovascular disease were included. Clinical and anthropometric data were collected. Biochemical parameters, including total cholesterol (TC), HDL, LDL, triglycerides, glucose, insulin and 25-hydroxyvitamin-D [25(OH)D] were measured. Women meeting three or more of the following criteria were diagnosed with MetS: waist circumference $>88 \mathrm{~cm}$, triglycerides $\geq 150 \mathrm{mg} / \mathrm{dL}, \mathrm{HDL}<50 \mathrm{mg} / \mathrm{dL}$, blood pressure $\geq 130 / 85 \mathrm{mmHg}$ and glucose $\geq 100 \mathrm{mg} / \mathrm{dL}$. Serum $25(\mathrm{OH}) \mathrm{D}$ levels were classified as sufficient ( $\geq 30 \mathrm{ng}$ / $\mathrm{mL})$, insufficient $(20-29 \mathrm{ng} / \mathrm{mL})$ or deficient $(<20 \mathrm{ng} / \mathrm{mL})$. ANOVA, chi-square test and logistic regression (odds ratio, OR) were used for statistical analysis.

Results: Serum 25(OH)D levels were sufficient in 148 women (32.0\%), insufficient in 151 (32.6\%) and deficient in $164(35.4 \%)$. Women with low 25(OH)D levels had higher TC, triglycerides, insulin and HOMA-IR levels ( $\mathrm{p}<0.05$ ). MetS was detected in $57.8 \%$ (182/315) of women with hypovitaminosis D (insufficient and deficient) and in $39.8 \%(59 / 148)$ of those with sufficient VD ( $\mathrm{p}=0.003)$. In a multivariate logistic regression analysis, a low 25(OH)D level $(<30 \mathrm{ng} / \mathrm{mL})$ was significantly associated with MetS (OR1.90, $95 \% \mathrm{CI}=1.26-2.85)$, high triglyceride levels (OR1.55, 95\%CI $=1.13-2.35)$, and low HDL levels (OR1.60, $95 \% \mathrm{CI}=1.19-2.40)(\mathrm{p}<0.05)$ compared with women with sufficient $25(\mathrm{OH}) \mathrm{D}$ levels, after adjusting for age, time since menopause, body mass index, smoking and physical exercise. The mean concentration of 25(OH)D decreased with increasing numbers of MetS components $(\mathrm{p}=0.016)$.

Conclusions: VD deficiency in postmenopausal women was associated with a higher prevalence of MetS. Women with VD deficiency had a higher risk of MetS, hypertriglyceridemia and low HDL than those with adequate levels.
\end{abstract}

\section{Introduction}

Nowadays, most women in urban societies have risk factors for cardiovascular disease (CVD) as a result of increases in the proportion of women older than 50 years, the prevalence of abdominal obesity, levels of physical inactivity, and the prevalence of modern eating habits [1]. Metabolic syndrome (MetS) is defined as a set of metabolic risk factors that include abdominal obesity, dyslipidemia, arterial hypertension, and dysglycemia [2]. This syndrome affects approximately $50 \%$ of the female population above the age of 50 and is associated with a threefold increase in morbidity and mortality due to CVD [1-3]. Metabolic syndrome is associated with a metabolic disorder called insulin resistance, in which the normal action of insulin is compromised [1]. Obesity is a proinflammatory state that contributes to insulin resistance, a condition suggested to be the causal factor of dyslipidemia and glucose intolerance [4].

Vitamin D (VD) deficiency and the increase in the prevalence of obesity are considered important public health issues. VD deficiency is recognized as the most common medical condition in the world [5]. An epidemiological study performed in 18 countries located at different latitudes, which assessed plasma concentrations of 25-hydroxyvitamin D [25(OH)D] in postmenopausal women, demonstrated low levels almost throughout the world. Overall, $64 \%$ of the participants had inadequate concentrations [6]. Recent evidence suggests a role of VD

\footnotetext{
* Corresponding author at: Department of Gynecology and Obstetrics, Botucatu Medical School, Sao Paulo State University - UNESP, Distrito de Rubião Júnior s/n, Botucatu, SP, Brazil.

E-mail address: epetri@fmb.unesp.br (E.A. Petri Nahas).
} 
deficiency in different non-communicable chronic diseases such as obesity, hypertension, diabetes and, consequently, MetS and CVD $[4,7,8]$. In a meta-analysis of 28 studies, elevated serum levels of $25(\mathrm{OH}) \mathrm{D}$ were associated with a $55 \%$ reduction in the incidence of diabetes, a $51 \%$ lower risk of MetS, and a 33\% lower risk of CVD [8]. Measurement of 25(OH)D levels in blood samples can be used to evaluate and monitor VD nutritional status effectively in humans since serum levels are the main indicator of body reserves [9].

Several studies of the general population have shown an inverse relationship in both genders of serum 25(OH)D levels with MetS, diabetes and insulin resistance [10-12]. However, despite evidence on the association of serum VD levels with MetS in different age and ethnic groups, data for postmenopausal women are sparse and contradictory. Some studies have demonstrated an inverse relationship between VD and MetS in postmenopausal women [13-15], but others not [16,17]. Thus, more clinical studies are needed to confirm the association between MetS and VD deficiency in postmenopausal women. The objective of this study, therefore, was to evaluate the association between VD deficiency and risk factors for MetS in postmenopausal women.

\section{Methods}

\subsection{Study design and sample selection}

This was a clinical, analytical, comparative, cross-sectional study. The study population consisted of women seen at the Climacteric and Menopause Outpatient Clinic of the Botucatu Medical School, Sao Paulo State University (UNESP), between March 2015 and November 2016. Women whose last menstruation occurred at least 12 months prior to this study and who were $\geq 45$ years old were included. Exclusion criteria were a known high cardiovascular risk due to existing or preexisting coronary heart disease, cerebrovascular arterial disease, abdominal aortic stenosis or aneurysm, peripheral artery disease, chronic kidney disease or renal failure (creatinine $>1.4 \mathrm{mg} / \mathrm{dl}$ ), insulin-dependent diabetes, liver disease, autoimmune disease, thyroid dysfunction, cancer, hyperparathyroidism, alcohol misuse, grade III obesity, and pharmacological use of VD (at any dose). Informed consent was obtained from all participants and the study was approved by the Research Ethics Committee of the Botucatu Medical School, UNESP.

\subsection{Clinical measurements}

The following data were collected on the day of the visit by individual interview: race, age, time since menopause, smoking status, use of hormone therapy (HT), a history of hypertension and diabetes, medication use, and level of physical activity. Blood pressure was measured with a standard aneroid sphygmomanometer on the right arm after a 5-min rest. The patient was sitting, with the forearm resting at the level of the precordium and the palm of the hand facing upwards. Smokers were defined as persons who reported smoking, regardless of the number of cigarettes smoked. Women who practiced aerobic exercise of moderate intensity for at least $30 \mathrm{~min}$, five times a week (150 min/week) or resistance exercise three times a week were classified as active. Metabolic syndrome was diagnosed if three or more of the following diagnostic criteria, proposed by the US National Cholesterol Education Program/Adult Treatment Panel III (NCEP/ATP III) [18], were met: waist circumference $>88 \mathrm{~cm}$; triglycerides $\geq 150 \mathrm{mg} / \mathrm{dL} ; \mathrm{HDL}<50 \mathrm{mg} / \mathrm{dL}$; blood pressure $\geq 130 / 85 \mathrm{mmHg}$ or the woman was receiving treatment for high blood pressure; fasting glucose $\geq 100 \mathrm{mg} / \mathrm{dL}$ or the woman was receiving treatment for hyperglycemia.

The anthropometric data included weight, height, body mass index (BMI $=$ weight $/$ height $^{2}$ ), and waist circumference. Weight and height were determined with a standard balance beam scale and a portable wall anthropometer, respectively, with the patient wearing light clothing and no shoes. The 2002 World Health Organization criteria were used to classify BMI: normal, $\leq 24.9 \mathrm{~kg} / \mathrm{m}^{2}$; overweight, $25-29.9 \mathrm{~kg} / \mathrm{m}^{2}$; grade I obesity, $30-34.9 \mathrm{~kg} / \mathrm{m}^{2}$; grade II obesity, $35-39.9 \mathrm{~kg} / \mathrm{m}^{2}$; grade III obesity, $40 \mathrm{~kg} / \mathrm{m}^{2}$ or more. Waist circumference was measured at the midpoint between the lowest rib and the top of the iliac crest, with the participant in the orthostatic position. Measurements were performed at the time of exhalation by a single examiner (EB Schmitt). Increased waist circumference was defined as a value over $88 \mathrm{~cm}$ [18].

\subsection{Laboratory assessment}

Blood samples for biochemical analysis were collected from each participant after a 12-h fast. Triglycerides, total cholesterol, high-density lipoprotein cholesterol (HDL), low-density lipoprotein cholesterol (LDL), glucose, and creatinine were measured by a colorimetric drychemistry method in an automated Vitros $950^{\circ}$ analyzer (JohnsonJohnson ${ }^{\circ}$, Rochester, NY, USA). The coefficient of variation was $2 \%$ for triglycerides, $2 \%$ for total cholesterol, $2 \%$ for HDL cholesterol and $1 \%$ for fasting glucose. The following values were defined as optimal: total cholesterol $<200 \mathrm{mg} / \mathrm{dL}, \mathrm{HDL}>50 \mathrm{mg} / \mathrm{dL}, \mathrm{LDL}<100 \mathrm{mg} / \mathrm{dL}$, triglycerides $<150 \mathrm{mg} / \mathrm{dL}$, and glucose $<100 \mathrm{mg} / \mathrm{dL}$. Insulin was measured by chemoluminescence with an automated Immulite $2000^{\circ} \mathrm{im}$ munoassay system (Diagnostic Products Corporation, Los Angeles, CA, USA). The normal range according to the method employed was $6.0-27.0 \mu \mathrm{IU} / \mathrm{mL}$ and the coefficient of variation was $3 \%$. Insulin resistance was determined by measurement of two plasma components (insulin and fasting glucose). The homeostasis model assessment of insulin resistance (HOMA-IR) was calculated using the following formula: insulin $(\mathrm{mIU} / \mathrm{mL}) \times$ glucose $(\mathrm{mg} / \mathrm{dL}) / 405$. Insulin resistance was defined as HOMA-IR $>2.7$. Serum 25(OH)D concentrations were assessed by a chemiluminescent immunoassay (Architect 25-OH-Vitamin D Assay Kit) in an automated Architect ${ }^{\circ}$ i2000 analyzer (Abbott ${ }^{\circ}$, Santa Clara, CA, USA). The detection limit was $1.9 \mathrm{ng} / \mathrm{mL}$ and the coefficient of variation was $<10 \%$. The serum $25(\mathrm{OH}) \mathrm{D}$ concentrations detected were within the range of $0.0-160.0 \mathrm{ng} / \mathrm{mL}$. Serum concentrations of 25(OH)D less than $30 \mathrm{ng} / \mathrm{mL}$ were classified as deficient and concentrations of $30 \mathrm{ng} / \mathrm{mL}$ or more as sufficient [9].

\subsection{Statistical analysis}

The desired sample size was estimated on the basis of data reported by Ford et al. [10], who found different serum 25(OH)D levels among women with and without MetS (20.3 and $22.9 \mathrm{ng} / \mathrm{mL}$, respectively). Considering this difference and assuming a $5 \%$ level of significance and allowing a $10 \%$ probability of a type II error ( $90 \%$ test power), the sample size set at 115 women or more per group (with and without MetS).

The serum 25(OH)D level was categorized as sufficient ( $\geq 30 \mathrm{ng}$ / $\mathrm{mL})$, insufficient $(20-29 \mathrm{ng} / \mathrm{mL})$ or deficient $(<20 \mathrm{ng} / \mathrm{mL})$, and the women were divided into three groups accordingly. The Shapiro-Walk test was used to determine whether the variables showed a normal distribution and the Levene test to determine homogeneity. The mean and standard deviation were calculated for quantitative variables, and frequency and percentage for qualitative variables. The clinical, anthropometric, and biochemical variables were compared between groups by one-way analysis of variance (ANOVA) and gamma distribution (asymmetric). The frequencies of categorical data were compared by the chi-square test. Multivariate logistic regression analyses were performed to estimate the odds ratio (OR) and 95\% confidence interval (CI) for the association between serum 25(OH)D levels (dependent variable) and the variables influencing the risk for MetS (independent variables), adjusted for age, time since menopause, BMI, smoking and physical exercise (confounding variables). All clinical and laboratory variables that presented a significant difference were submitted to stepwise multiple logistic regression. Only statistically significant results are reported. We used a test for linear trend to compare 
Table 1

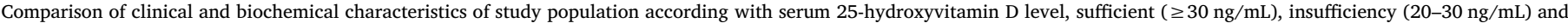
deficiency $(<20 \mathrm{ng} / \mathrm{mL})$.

\begin{tabular}{|c|c|c|c|c|}
\hline Characteristics & Sufficient $(n=148)$ & Insufficiency $(\mathrm{n}=151)$ & Deficiency $(n=164)$ & $p$ value \\
\hline Age, mean (SD), y & $56.8(6.6) \mathrm{a}$ & $57.9(7.6) \mathrm{a}$ & $58.5(7.7) \mathrm{a}$ & 0.059 \\
\hline Age at menopause, mean (SD), y & $47.6(5.1) \mathrm{a}$ & $47.9(5.0) \mathrm{a}$ & $47.3(5.6) \mathrm{a}$ & 0.522 \\
\hline Time since menopause, mean (SD), y & $8.9(7.1) \mathrm{a}$ & $10.8(7.2) \mathrm{a}$ & $9.8(8.9) \mathrm{a}$ & $0.079^{\S}$ \\
\hline SBP, mean (SD), mmHg & $130.1(18.3) \mathrm{a}$ & $132.1(21.4) \mathrm{a}$ & $133.6(20.8) \mathrm{a}$ & 0.311 \\
\hline DBP, mean (SD), mmHg & $81.4(10.8) \mathrm{a}$ & 82.3 (12.7)a & $81.5(12.5) \mathrm{a}$ & 0.758 \\
\hline BMI, mean (SD), $\mathrm{kg} / \mathrm{m}^{2}$ & $28.7(5.0) \mathrm{a}$ & $29.1(5.5) \mathrm{a}$ & $29.3(5.0) \mathrm{a}$ & 0.578 \\
\hline WC, mean (SD), cm & $92.9(12.4) \mathrm{a}$ & 94.8 (13.4)a & 93.4 (11.7)a & 0.427 \\
\hline 25(OH)D, mean (SD), ng/mL & $35.9(5.7) a$ & $25.1(2.9) \mathrm{b}$ & $14.2(3.8) \mathrm{c}$ & $<0.0001$ \\
\hline Total Colesterol, mean (SD), mg/dL & 200.7 (36.9)a & $208.3(40.7) b$ & $209.4(45.9) b$ & 0.031 \\
\hline HDL, mean (SD), mg/dL & $51.9(13.1) \mathrm{a}$ & $50.1(12.5) \mathrm{a}$ & $49.9(11.7) a$ & $0.317^{\S}$ \\
\hline LDL, mean (SD), mg/dL & $119.4(33.8) a$ & $123.8(36.2) \mathrm{a}$ & $128.5(42.8) \mathrm{a}$ & 0.1199 \\
\hline Triglycerides, mean (SD), mg/dL & $147.1(77.3) \mathrm{a}$ & $159.2(74.4) \mathrm{b}$ & $166.5(97.8) \mathrm{b}$ & $0.019^{\S}$ \\
\hline Glucose, mean (SD), mg/dL & $96.5(21.2) \mathrm{a}$ & $99.8(29.8) \mathrm{a}$ & $99.0(21.3) \mathrm{a}$ & $0.127^{\S}$ \\
\hline Insulin, mean (SD), $\mu \mathrm{UI} / \mathrm{mL}$ & $8.3(7.2) \mathrm{a}$ & $10.9(8.3) \mathrm{b}$ & $10.7(6.8) \mathrm{b}$ & $0.001^{\S}$ \\
\hline HOMA-IR, mean (SD) & $2.1(2.4) \mathrm{a}$ & $2.9(2.7) \mathrm{b}$ & $2.7(1.9) \mathrm{b}$ & $0.001^{\S}$ \\
\hline White Race, n (\%) & 136 (91.9)a & 138 (91.4)a & $146(89.0) \mathrm{a}$ & $0.379^{\#}$ \\
\hline Smoking, n (\%) & $18(12.2) \mathrm{a}$ & $23(15.2) \mathrm{a}$ & $24(14.6) \mathrm{a}$ & $0.089^{\#}$ \\
\hline Physical exercise, $\mathrm{n}(\%)$ & $38(25.7) a$ & $32(21.2) \mathrm{a}$ & $45(27.4) \mathrm{a}$ & $0.459^{\#}$ \\
\hline HT use, n (\%) & $53(35.8) a$ & $50(33.1) \mathrm{a}$ & $52(31.7) \mathrm{a}$ & $0.571^{\#}$ \\
\hline Hypertension, n (\%) & $69(46.6)$ & $76(50.3)$ & $85(51.8)$ & $0.289^{\#}$ \\
\hline Diabetes, n (\%) & $22(14.9)$ & $24(15.9)$ & $27(16.4)$ & $0.926^{\#}$ \\
\hline Metabolic Syndrome, n (\%) & $59(39.8) a$ & $86(56.9) \mathrm{b}$ & $96(58.5) \mathrm{b}$ & $0.001^{\#}$ \\
\hline
\end{tabular}

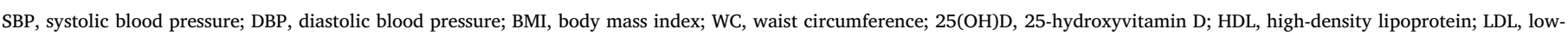
density lipoprotein; HOMA-IR, homeostasis model assessment of insulin resistance; HT, hormone therapy.

p-value (a,b) show significant differences between groups $(\mathrm{p}<0.05)$ and $(\mathrm{a}, \mathrm{a})$ without difference $(\mathrm{p}>0.05)\left(\right.$ ANOVA, Gamma distribution ${ }^{\S}$ or Chi-square test $^{\#}$ ).

The bold values in the tables are the values that were statistically significant as reported in the footnote of the table.

proportions across the serum 25(OH)D levels according to the number of MetS components. The statistical tests were bilateral and a level of significance of $5 \%$ was adopted. All analyses were performed using the Statistical Analysis System (SAS) 9.2 program.

\section{Results}

The 463 postmenopausal women comprising the study sample had their serum 25(OH)D levels classified as sufficient $(\geq 30 \mathrm{ng} / \mathrm{mL}$, $\mathrm{n}=148$ ), insufficient $(20-29 \mathrm{ng} / \mathrm{mL}, \mathrm{n}=151)$ or deficient $(<20 \mathrm{ng}$ / $\mathrm{mL}, \mathrm{n}=164$ ). In further analyses the last two groups were combined to give a single group of women with hypovitaminosis $\mathrm{D}$, while those with sufficient levels of 25(OH)D were used as a control group.

The clinical, anthropometric and laboratory variables submitted to statistical comparison are shown in Table 1. The three groups were homogenous in terms of the following variables: age, age at menopause, time since menopause, systolic and diastolic blood pressure, waist circumference, BMI, HDL, LDL, and glucose ( $\mathrm{p}>0.05)$. Approximately $90 \%$ of our participants were white, with no difference between groups. Significant differences were observed in mean total cholesterol, triglycerides, insulin and HOMA-IR. With respect to BMI, patients were on average overweight (BMI between 25.0 and $29.9 \mathrm{~kg} / \mathrm{m}^{2}$ ) and exhibited central body fat deposition (waist circumference $>88 \mathrm{~cm})(\mathrm{p}>0.05)$ (Table 1).

Biochemical analysis showed mean total cholesterol, triglycerides and insulin above the desirable levels in women with hypovitaminosis $\mathrm{D}(\mathrm{p}<0.05)$. In these women, the mean HOMA-IR values indicated insulin resistance $(>2.7)$. There was no difference between groups in the frequency of HT use, smoking, levels of physical activity, arterial hypertension or diabetes $(\mathrm{p}>0.05)$ (Table 1$)$.

According to the NCEP/ATP III criteria, 57.8\% (182/315) of the women with hypovitaminosis D and $39.8 \%$ (59/148) of the control group were classified as having MetS. This difference in the prevalence of MetS between groups was significant ( $\mathrm{p}=0.003$ ) (Table 2). Among the diagnostic criteria, abdominal obesity (waist circumference $>88$ $\mathrm{cm}$ ) and increased blood pressure were the most prevalent in women with normal or deficient $25(\mathrm{OH}) \mathrm{D}$, affecting $62.2 \%$ and $67.6 \%$ and
Table 2

Multivariate-adjusted stratified analysis between serum 25-hydroxyvitamin D (sufficient $\geq 30 \mathrm{ng} / \mathrm{mL}$ and deficiency $<30 \mathrm{ng} / \mathrm{mL}$ ), and metabolic syndrome and its components.

\begin{tabular}{lllll}
\hline & $\begin{array}{l}\text { Sufficient } \\
\mathrm{n}(\%)\end{array}$ & $\begin{array}{l}\text { Deficiency } \\
\mathrm{n}(\%)\end{array}$ & OR (95\%) & $\begin{array}{l}\text { Valor de } \\
p^{\mathrm{b}}\end{array}$ \\
\hline Metabolic Syndrome & $59(39.8)$ & $184(57.9)$ & $\begin{array}{l}1.90 \\
(1.26-2.85)\end{array}$ & $\mathbf{0 . 0 4 9}$ \\
WC $(>88 \mathrm{~cm})$ & $92(62.2)$ & $215(67.6)$ & $\begin{array}{l}1.22 \\
(0.80-1.86)\end{array}$ & 0.348 \\
Triglycerides $(\geq 150 \mathrm{mg} /$ & $53(35.8)$ & $150(47.2)$ & $\begin{array}{l}1.55 \\
(1.13-2.35)\end{array}$ & $\mathbf{0 . 0 3 6}$ \\
dL) & $69(46.6)$ & $180(56.6)$ & $\begin{array}{l}1.60 \\
(1.19-2.40)\end{array}$ & $\mathbf{0 . 0 2 2}$ \\
HDL $(<50 \mathrm{mg} / \mathrm{dL})$ & $32(21.6)$ & $72(22.6)$ & $\begin{array}{l}0.98 \\
(0.60-1.59)\end{array}$ & 0.932 \\
Glucose $(\geq 100 \mathrm{mg} / \mathrm{dL})$ & & $219(68.8)$ & $\begin{array}{l}1.23 \\
(0.79-2.85)\end{array}$ \\
BP $(\geq 135 / 85 \mathrm{mmHg})$ & $98(66.2)$ & & 0.356
\end{tabular}

WC, waist circumference; HDL, high-density lipoprotein; BP, blood pressure.

The bold values in the tables are the values that were statistically significant as reported in the footnote of the table.

${ }^{\text {a }}$ Odds Ratio (OR) adjusted for age, time of menopause, body mass index, smoking and physical exercise.

${ }^{\mathrm{b}}$ Significantly different if $p<0.05$ (Logistic regression).

$66.2 \%$ and $68.8 \%$ of the participants, respectively ( $p>0.05$ ). Analysis of the risk adjusted for age, time since menopause, BMI, smoking and physical exercise showed that patients with VD deficiency were more likely to have MetS (OR 1.90; 95\%CI 1.26-2.85), hypertriglyceridemia (OR 1.55; 95\%CI 1.13-2.35) and HDL below the desirable level (OR 1.60; 95\%CI 1.19-2.40) compared with the control group $(\mathrm{p}<0.05)$ (Table 2).

The mean VD concentration adjusted for age, time since menopause and BMI was $25.6 \pm 10.4 \mathrm{ng} / \mathrm{mL}$ for participants without MetS and $23.4 \pm 9.5 \mathrm{ng} / \mathrm{mL}$ for women with MetS $(\mathrm{p}=0.0146)$. Fig. 1 presents the serum 25(OH)D levels according to the numbers of MetS components. The serum 25(OH)D levels significantly decreased with increasing numbers of MetS components: $28.2 \pm 10.5 \mathrm{ng} / \mathrm{mL}$ among those with none; $25.9 \pm 9.6 \mathrm{ng} / \mathrm{mL}$ among those with one component; 


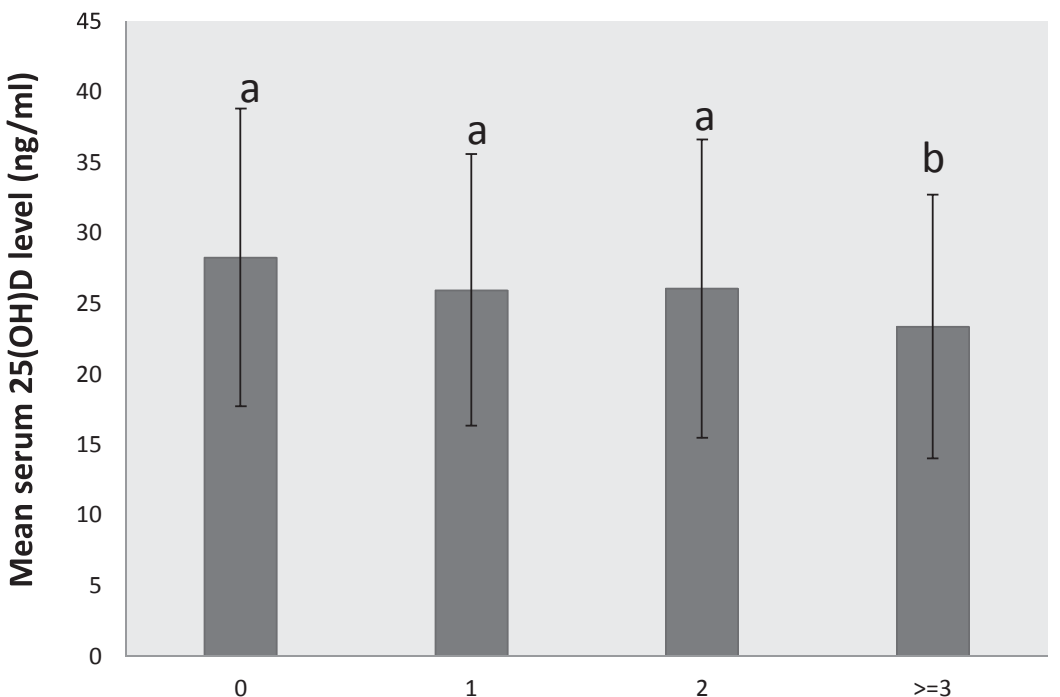

Number of the components of metabolic syndrome
Fig. 1. Serum 25-hydroxyvitamin D [25(OH)D] levels according to number of the components of metabolic syndrome.

Data are shown as mean \pm SD of 25(OH)D serum levels: $28.2 \pm 10.5 \mathrm{ng} / \mathrm{mL}$ without component, $25.9 \pm 9.6 \mathrm{ng} / \mathrm{mL}$ with one component, $26.0 \pm 9.5 \mathrm{ng} / \mathrm{mL}$ with two components and $23.3 \pm 8.3 \mathrm{ng} / \mathrm{mL}$ with three or more components $(P$ for trend $=0.0163$, adjusted for age, time since menopause and body mass index). Different letters $(a, b)$ show significant differences among groups and the same letter $(a, a)$ no difference ( $p>0.05$ ).
$26.0 \pm 9.5 \mathrm{ng} / \mathrm{mL}$ among those with two components; and $23.3 \pm 8.3 \mathrm{ng} / \mathrm{mL}$ among those with three or more components ( $p$ for trend $=0.0163$ ).

\section{Discussion}

In the present study, an association was observed between VD deficiency and MetS in postmenopausal women. Women with VD deficiency had a higher risk of developing MetS, hypertriglyceridemia and low HDL levels than women with adequate levels of this vitamin. In addition, women with hypovitaminosis D had higher levels of total cholesterol, triglycerides, insulin and HOMA-IR than those with adequate VD concentrations. These results agree with studies involving the general population that showed an association between VD deficiency and the presence of MetS [7,10-12]. A meta-analysis evaluating the association of VD with MetS and diabetes included 17 prospective studies with 210,107 participants and 15,899 metabolic events. The mean follow-up was 10 years. The results showed an inverse association between VD concentrations and the risk for diabetes (OR 0.81), insulin resistance (OR 0.84), and MetS (OR 0.86). Moderate heterogeneity was found for diabetes among 14 studies. The authors concluded that interventions designed to maintain adequate serum VD levels might be useful to prevent metabolic disease [19].

Although it has been recognized that postmenopausal women are susceptible to low serum VD levels and are at an increased risk of MetS, few studies have evaluated the prevalence of MetS and its association with serum VD levels in postmenopausal women. The present study demonstrated a significant association between hypovitaminosis D and the presence of MetS in postmenopausal women, in agreement with a few other studies [13-15]. A cross-sectional study that evaluated 292 postmenopausal women aged 50-79 years participating in the Women's Health Initiative Calcium-Vitamin D study found an inverse association between serum 25(OH)D levels and adiposity, triglyceride levels, triglyceride:HDL-cholesterol ratio, and presence of MetS. There was no association with LDL, HDL, insulin, glucose, or HOMA-IR [13]. In a study investigating 478 postmenopausal Korean women, low serum 25(OH)D levels were significantly associated with the presence of MetS and with metabolic components, especially hypertriglyceridemia and arterial hypertension [14]. Another study using data from the 2008-2010 Korean NHANES evaluated 4364 postmenopausal women. The authors found no significant association between serum 25(OH)D and the prevalence of MetS. However, women in the upper percentile of VD concentration had a lower prevalence of hypertension, hypertriglyceridemia and reduced HDL than women in the lower percentile [15]. A recent study analyzed the relationship between serum 25(OH)D concentrations and the distribution of body fat in a sample of 62 postmenopausal women. The authors found a negative correlation between 25(OH)D and waist circumference, HDL and HOMA-IR, but no association with the presence of MetS was observed [17].

Evidence from an increasing number of studies suggests that 25(OH) $\mathrm{D}$ levels are inversely associated with adiposity, lipemia and glucose homeostasis [20]. In the present study, women with VD deficiency had higher HOMA-IR values, indicating the presence of insulin resistance, than women with sufficient VD levels. Studies have demonstrated a negative correlation between serum VD levels and insulin resistance $[7,10,21,22]$. It is accepted that central obesity and insulin resistance are core drivers of the MetS. Ford et al. [7], evaluating North American data from the 2003-2006 National Health and Nutrition Examination Survey (NHANES), found significantly lower serum VD concentrations in subjects with MetS [7]. Using the same data (NHANES, 2003-2006), Maki et al. [10] studied the association between VD levels and the prevalence of MetS in adults aged over 20 years. The authors observed that increased waist circumference, low HDL cholesterol and increased insulin resistance evaluated by HOMA-IR were associated with reduced serum 25(OH)D concentrations [10].

The serum concentration of VD decreased linearly with increasing number of MetS components among the women studied here. Mean VD levels were markedly reduced among women with three or more components of MetS (i.e. meeting the diagnostic criteria for MetS itself), even after adjusting for different factors. There are several possible physiopathological mechanisms that could explain the effect of VD on the components of MetS. The most plausible explanation is that VD influences insulin secretion and sensitivity, which play a major role in MetS. Different biological factors support the association of VD deficiency with insulin resistance and diabetes. The VD receptor (VDR) is expressed in insulin-secreting pancreatic beta cells and in peripheral target tissues such as skeletal muscle and adipose tissue [23]. Vitamin D deficiency can compromise the capacity of beta cells to convert proinsulin to insulin. In humans, polymorphisms in the VDR genes have been associated with variations in insulin secretion and sensitivity [24]. Vitamin D indirectly affects insulin sensitivity in skeletal muscle and adipose tissue by regulating the levels of extracellular calcium, which is essential for insulin-mediated intracellular processes [25]. In addition, diabetes and VD deficiency share some risk factors such as age, nonCaucasian ethnicity, obesity, and physical inactivity (less outdoor time and reduced sun exposure). Although VD deficiency is prevalent 
throughout across the adult age range, the reduction in outdoor activities and the possible decrease in the capacity of aged skin to synthesize $25(\mathrm{OH}) \mathrm{D}$ may contribute to high prevalence of VD deficiency in postmenopausal women.

In the present study, women with VD deficiency had a higher risk of hypertriglyceridemia and low HDL concentrations. In a literature review, observational studies showed that subjects with high serum VD levels had a more favorable lipid profile than those with VD deficiency [26]. Martins et al. [27] studied the association between serum 25(OH) D levels and risk factors of CVD in North American adults (7186 men and 7902 women) using data from the NHANES. The participants with VD deficiency were more likely to have elevated serum triglyceride levels. After adjusting for age, gender and race, $32.9 \%$ of the subjects with $\mathrm{VD}<21 \mathrm{ng} / \mathrm{mL}$ had triglyceride levels of $150 \mathrm{mg} / \mathrm{dL}$ or higher versus $23.8 \%$ among those with VD $\geq 37 \mathrm{ng} / \mathrm{mL}$. The OR for elevated triglycerides was 1.47 for subjects with low VD levels compared with those with adequate levels of this vitamin [27]. A longitudinal study involving 1762 participants demonstrated that an increase in serum 25(OH)D concentrations was associated with a significant reduction in triglyceride levels [28]. One likely mechanism underlying the inverse association between serum lipids and VD levels is a reduction in the intestinal absorption and synthesis of lipids and a decrease in lipolysis with increasing VD concentrations [28].

Although the mechanisms responsible for the association between VD status and dyslipidemia are not well understood, an animal study reported a positive association between plasma VD concentration and HDL, concluding that a reduction in VD could contribute to an atherogenic lipid profile, which is an important risk factor for the progression of coronary artery disease [29]. A significant positive correlation between serum 25(OH)D and of apolipoprotein (Apo) A-I with HDL levels has been reported, a correlation that is independent of calcium [30]. In this respect, studies have demonstrated that VD can influence the formation of HDL particles [29-31]. Furthermore, it has been proposed that VDR interferes with cholesterol levels by regulating, at the genetic level, the synthesis of bile acids from cholesterol. However, some common factors can be attributed to both high serum 25( $\mathrm{OH}) \mathrm{D}$ levels and a favorable lipid profile. People engaging in high levels of outdoor physical exercise, which would raise 25(OH)D levels due to greater sun exposure, may be more likely also to have healthy eating habits, which could favorably affect their lipid profile [29]. Thus, intervention studies are necessary to detect a causal relationship between 25(OH)D and lipid levels.

Several epidemiological studies have demonstrated that obese individuals have lower serum concentrations of $25(\mathrm{OH}) \mathrm{D}$, with an inverse association between VD concentration and BMI and waist circumference [32-34]. The mechanisms involved are not fully described, but it is possible that the sequestration of VD metabolites in adipose tissue decreases their bioavailability $[35,36]$. Expression of both the VDR and the 25-hydroxyvitamin D 1 $\alpha$-hydroxylase (CYP27B1) gene has been demonstrated in human adipocytes. There is evidence that VD affects body fat by inhibiting adipogenic transcription factors and by accumulating lipids during adipocyte differentiation. VD metabolites also influence adipocytokine production and the inflammatory response in adipose tissue [36]. Thus, VD deficiency may impair the normal metabolic functioning of adipose tissue. And because of the importance of adipose tissue in energy balance, lipid metabolism and inflammation, VD concentration can have a significant impact on the maintenance of metabolic health [4].

The present study has some limitations. First, although the results were adjusted for some potential confounders, the cross-sectional design of the study does not permit a causal relationship between serum VD level and MetS to be established. Second, we were unable to analyze factors such as the amount of exposure to sunlight and dietary VD and calcium intake, which could have affected serum 25(OH)D levels, because that information was not available. In addition, VD was measured only once in each participant.

\section{Conclusions}

In the present study, an association was observed between VD deficiency and MetS in postmenopausal women. Women with VD deficiency had a higher risk of MetS, hypertriglyceridemia and low HDL than those with adequate levels. These results suggest that the maintenance of adequate serum levels of 25(OH)D in postmenopausal women may reduce the risk of developing MetS, a condition that is known to be related to cardiovascular events and mortality in this group.

\section{Contributors}

EBS participated in the project conception, data collection, data analysis and manuscript writing/editing.

JN-N participated in the project conception, data analysis, manuscript writing/editing, and revising the article.

FB-D was involved in data collection, data analysis and revision of the paper.

PFP was involved in data collection, data analysis and revision of the paper.

CLO took part in the statistical analysis of the results and in the writing of the paper.

EAPN (the supervisor of the PhD project) participated in the project conception, data analysis, manuscript writing/editing, and revising the article.

All authors saw and approved the final version.

\section{Conflict of interest}

The authors declare that they have no conflict of interest.

\section{Funding}

This study was supported by the Sao Paulo Research Foundation (FAPESP) (grant number 2014/19382-3).

\section{Ethical approval}

All study participants gave informed consent to participate in this research. The study was conducted in accordance with the ethical standards set forth in the Helsinki Declaration (1983). The Research Ethics Committee of the Botucatu Medical School, Sao Paulo State University - UNESP, approved the study.

\section{Provenance and peer review}

This article has undergone peer review.

\section{References}

[1] S. Mottillo, K.B. Filion, J. Genest, L. Joseph, L. Pilote, P. Poirier, S. Rinfret, E.L. Schiffrin, M.J. Eisenberg, The metabolic syndrome and cardiovascular risk a systematic review and meta-analysis, J. Am. Coll. Cardiol. 56 (2010) 1113-1132.

[2] E.A.P. Nahas, N.P. Padoani, J. Nahas-Neto, F.L. Orsatti, A.P. Tardivo, R. Dias, Metabolic syndrome and its associated risk factors in Brazilian postmenopausal women, Climacteric 12 (2009) 431-438.

[3] M.J. Gurka, A. Vishnu, R.J. Santen, M.D. DeBoer, Progression of metabolic syndrome severity during the menopausal transition, J. Am. Heart Assoc. 5 (2016) e003609.

[4] R.C. Strange, K.E. Shipman, S. Ramachandran, Metabolic syndrome: a review of the role of vitamin D in mediating susceptibility and outcome, World J. Diabetes 6 (2015) 896-911.

[5] J. Hilger, A. Friedel, R. Herr, T. Rausch, F. Roos, D.A. Wahl, D.D. Pierroz, P. Weber, K. Hoffmann, A systematic review of vitamin D status in populations worldwide, Br. J. Nutr. 111 (2014) 23-45.

[6] P. Lips, D. Hosking, K. Lippuner, J.M. Norquist, L. Wehren, G. Maalouf, S. Ragi-Eis, J. Chandler, The prevalence of vitamin D inadequacy amongst women with osteoporosis: an international epidemiological investigation, J. Inter. Med. 260 (2006) 245-254. 
[7] E.S. Ford, G. Zhao, C. Li, W.S. Pearson, Serum concentrations of vitamin D and parathyroid hormone and prevalent metabolic syndrome among adults in the United States, J. Diabetes 1 (2009) 296-303.

[8] J. Parker, O. Hashmi, D. Dutton, A. Mavrodaris, S. Stranges, N.B. Kandala, A. Clarke, O.H. Franco, Levels of vitamin D and cardiometabolic disorders: systematic review and meta-analysis, Maturitas 65 (2010) 225-236.

[9] B. Dawson-Hughes, R.P. Heaney, M.F. Holick, P. Lips, P.J. Meunier, R. Vieth, Estimates of optimal vitamin D status, Osteoporos. Int. 16 (2005) 713-716.

[10] K.C. Maki, V.L. Fulgoni, D.R. Keast, T.M. Rains, K.M. Park, M.R. Rubin, Vitamin D intake and status are associated with lower prevalence of metabolic syndrome in U.S. adults: National Health and Nutrition Examination Surveys 2003-2006, Metab. Syndr. Relat. Dis. 10 (2012) 363-372.

[11] S.Y. Ju, H.S. Jeong, H. Kim, Blood vitamin D status and metabolic syndrome in the general adult population: a dose-response metaanalysis, J. Clin. Endocrinol. Metab. 99 (2014) 1053-1063.

[12] A. Vitezova, M.C. Zillikens, T.W. van Herpt, E.J. Sijbrands, A. Hofman, A.G. Uitterlinden, O.H. Franco, J.C. Kiefte-de Jong, Vitamin D status and metabolic syndrome in the elderly: the Rotterdam Study, Eur. J. Endocrinol. 172 (2015) 327-335.

[13] S.A. Chacko, Y. Song, J.E. Manson, L. Van Horn, C. Eaton, L.W. Martin, A. McTiernan, J.D. Curb, J. Wylie-Rosett, L.S. Phillips, R.A. Plodkowski, S. Liu, Serum 25-hydroxyvitamin D concentrations in relation to cardiometabolic risk factors and metabolic syndrome in postmenopausal women, Am. J. Clin. Nutr. 94 (2011) 209-217.

[14] H.R. Song, C.H. Park, Low serum vitamin D level is associated with high risk of metabolic syndrome in post-menopausal women, J. Endocrinol. Invest. 36 (2013) 791-796.

[15] S.J. Chon, B.H. Yun, Y.S. Jung, S.H. Cho, Y.S. Choi, S.Y. Kim, B.S. Lee, S.K. Seo, Association between vitamin D status and risk of metabolic syndrome among Korean postmenopausal women, PLoS One 9 (2014) e89721.

[16] S. Moghassemi, A. Marjani, The effect of short-term vitamin D supplementation on lipid profile and blood pressure in post-menopausal women: a randomized controlled trial, Iran. J. Nurs. Midwifery Res. 19 (2014) 517-521.

[17] P. Andreozzi, W. Verrusio, G. Viscogliosi, M.L. Summa, N. Gueli, M. Cacciafesta, C.V. Albanese, Relationship between vitamin D and body fat distribution evaluated by DXA in postmenopausal women, Nutrition 3 (2016) 687-692.

[18] NCEP - Expert Panel on Detection E, Treatment of high blood cholesterol in A. executive summary of the third report of the National Cholesterol Education Program (NCEP) expert panel on detection, evaluation, and treatment of high blood cholesterol in adults (adult treatment panel III), JAMA 285 (2001) 2486-2497.

[19] H. Khan, S. Kunutsor, O.H. Franco, R. Chowdhury, Vitamin D, type 2 diabetes and her metabolic outcomes: a systematic review and meta-analysis of prospective studies, Proc. Nutr. Soc. 72 (2013) 89-97.

[20] S.J. Wimalawansa, Associations of vitamin D with insulin resistance, obesity, type 2 diabetes, and metabolic syndrome, J. Steroid Biochem. Mol. Biol. 20 (2016) pii: S0960-0760(16)30253-9.
[21] B. Schottker, C. Herder, D. Rothenbacher, L. Perna, H. Muller, H. Brenner, Serum 25-hydroxyvitamin D levels and incident diabetes mellitus type 2: a competing risk analysis in a large population-based cohort of older adults, Eur. J. Epidemiol. 28 (2013) 267-275.

[22] Y. Song, L. Wang, A.G. Pittas, L.C. Del Gobbo, C. Zhang, J.E. Manson, F.B. Hu, Blood 25-hydroxy vitamin $\mathrm{D}$ levels and incident type 2 diabetes: a meta-analysis of prospective studies, Diabetes Care 36 (2013) 1422-1428.

[23] R. Bland, D. Markovic, C.E. Hills, S.V. Hughes, S.L. Chan, P.E. Squires, M. Hewison, Expression of 25-hydroxyvitamin D3-1alpha-hydroxylase in pancreatic islets, J. Steroid Biochem. Mol. Biol. 89-90 (2004) 121-125.

[24] J.Y. Oh, E. Barrett-Connor, Association between vitamin D receptor polymorphism and type 2 diabetes or metabolic syndrome in community-dwelling older adults: the Rancho Bernardo Study, Metabol. Clin. Exp. 51 (2002) 356-359.

[25] A.G. Pittas, J. Lau, F.B. Hu, B. Dawson-Hughes, The role of vitamin D and calcium in type 2 diabetes, a systematic review and meta-analysis, J. Clin. Endocrinol. Metab. 92 (2007) 2017-2029.

[26] D. Challoumas, Vitamin D supplementation and lipid profile: what does the best available evidence show? Atherosclerosis 235 (2014) 130-139.

[27] D. Martins, M. Wolf, D. Pan, A. Zadshir, N. Tareen, R. Thadhani, A. Felsenfeld, B. Levine, R. Mehrotra, K. Norris, Prevalence of cardiovascular risk factors and the serum levels of 25-hydroxyvitamin D in the United States: data from the Third National Health and Nutrition Examination Survey, Arch. Intern. Med. 167 (2007) 1159-1165.

[28] R. Jorde, G. Grimnes, Vitamin D and metabolic health with special reference to the effect of vitamin D on serum lipids, Prog. Lipid Res. 50 (2011) 303-312.

[29] H. Wang, N. Xia, Y. Yang, D. Peng, Influence of vitamin D supplementation on plasma lipid profiles: a meta-analysis of randomized controlled trials, Lipids Health Dis. 11 (2012) 42.

[30] F.R. Pérez-López, Vitamin D metabolism and cardiovascular risk factors in postmenopausal women, Maturitas 62 (2009) 248-262.

[31] R. Kazlauskaite, L.H. Powell, C. Mandapakala, J.F. Cursio, E.F. Avery, J. Calvin, Vitamin D is associated with atheroprotective high-density lipoprotein profile in postmenopausal women, J. Clin. Lipidol. 4 (2010) 113-119.

[32] S. Arunabh, S. Pollack, J. Yeh, J.F. Aloia, Body fat content and 25-hydroxyvitamin D levels in healthy women, J. Clin. Endocrinol. Metab. 88 (1) (2003) 157-161.

[33] A.T. McGill, J.M. Stewart, F.E. Lithander, C.M. Strik, S.D. Poppitt, Relationships of low serum vitamin D3 with anthropometry and markers of the metabolic syndrome and diabetes in overweight and obesity, Nutr. J. 7 (2008) 4.

[34] E. Taheri, A. Saedisomeolia, M. Djalali, M. Qorbani, M. MadaniCivi, The relationship between serum 25-hydroxy vitamin D concentration and obesity in type 2 diabetic patients and healthy subjects, J. Diabetes Metab. Dis. 11 (1) (2012) 16.

[35] M. Blum, G. Dolnikowski, E. Seyoum, S.S. Harris, S.L. Booth, J. Peterson, E. Saltzman, B. Dawson-Hughes, Vitamin D3 in fat tissue, Endocrine 33 (1) (2008) 90-94.

[36] C. Ding, D. Gao, J. Wilding, P. Trayhurn, Bing C. Vitamin, D signalling in adipose tissue, Br. J. Nutr. 108 (11) (2012) 1915-1923. 